\title{
GASTRONOMY TOURISM - A TOOL FOR PROMOTING JHARKHAND AS A TOURIST DESTINATION
}

\author{
Mohinder Chand, ${ }^{*}$ Ashish Dahiya, ${ }^{* *}$ Lata S. Pati ${ }^{* * *}$
}

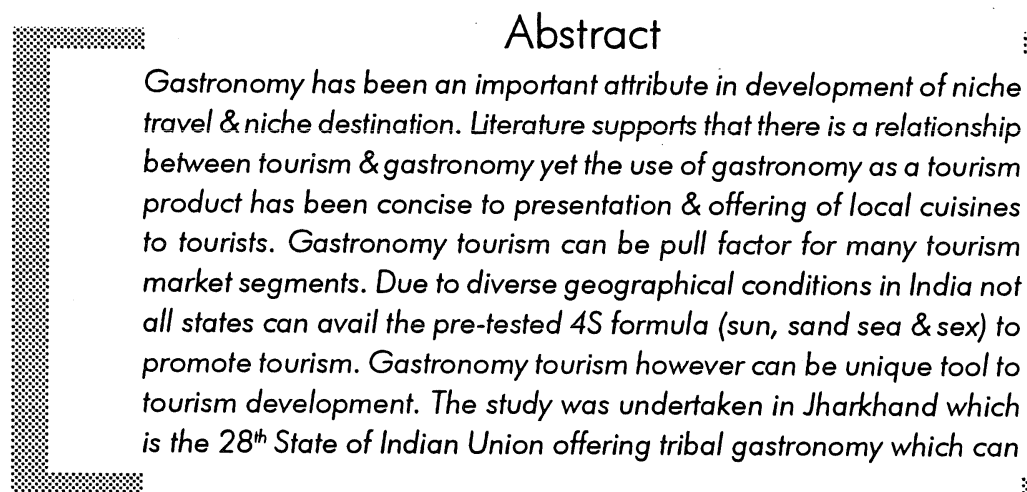

* Mohinder Chand - Reader, Department of Tourism \& Hotel Management, Kurukshetra University, Kurukshetra - Haryana. e-mail : mohinderchand@rediffmail.com

** Corresponding Author - Ashish Dahiya - Faculty, Department of Hotel Management, Birla Institute of Technology, Deemed University, Mesra - Ranchi 835215, Ph- 09431175462, e-mail : adahiya@bitmesra.ac.in

*** Lata S.Patil - Vice Principal, Bharati Vidyapeeth, College of Hotel \& Tourism Management Studies, Sector 8, C.B.D. Belapur Navi, Mumbai-400614, e-mail : lataspatil@yahoo.com 

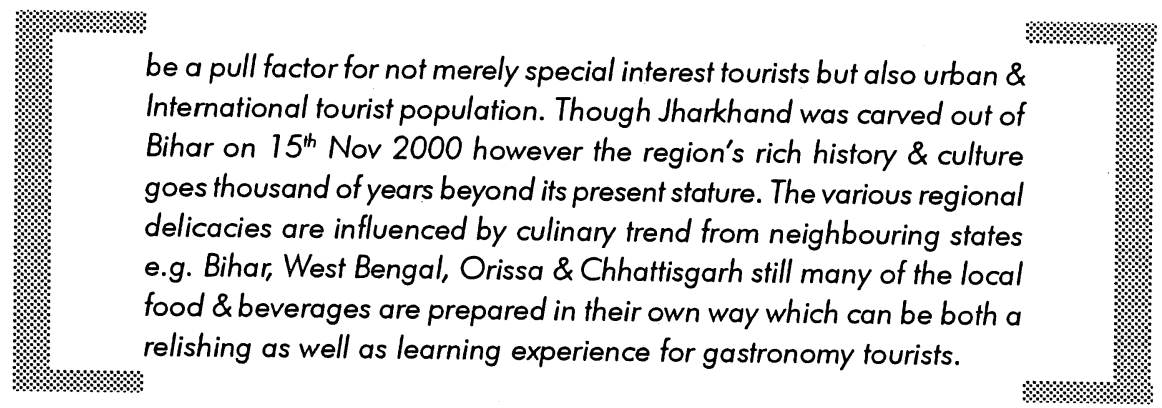

\section{Gastronomy \& Tourism- an Introduction}

Gastronomy is often referred to exclusively as the art of cooking and good eating; however, this can be considered as one part of this discipline. Some people also suggest that gastronomy is the study of the relationship between culture and food. The Encyclopedia Britannica (2000) defines gastronomy as: 'the art of selecting, preparing, serving, and enjoying fine food'. Originally gastronomy was for the nobility, but over time the concept has also come to include the 'peasant food' typical of regional and local cuisine. We can also say that one who is seriously involved in gastronomy is often involved in tasting, preparing, experiencing, experimenting, researching, discovering, understanding, and writing about food, and, usually but not exclusively, about beverage say wine. Thus it is very closely connected to beverages. Gastronomy often involves an understanding and appreciation of chemistry, literature, biology, geology, history, agronomy, anthropology, music, philosophy, psychology, and sociology. One can therefore argue that gastronomy is a complex, interdisciplinary activity (Jakša Kivela \& John C. Crotts). Gastronomy \& culinary are terms which are interchanged with each other. Etymologically, the word gastronomy is derived from Greek gastros, meaning stomach, and gnomos, knowledge or law. Culinary (Culinaria), on the other hand, describes a country's or region's dishes, foods, and food preparation techniques, which give rise to the country's or region's distinctive cuisine. So far in Indian tourism phenomena culinary is used extensively however the scope of gastronomy in Indian Tourism is a new area of study.

It's an old saying "The way to win one's heart is through stomach". Our sensory perceptions play a major psychological and physiological role in our appraisal and appreciation of food, as they do for other experiences at a destination. Quite often in Indian hospitality sector in organised sector the recipes are standardised \& in unorganised sector the quality is many a times is a matter of question. Thus the tourists do get a culinary experience of tasting the food. However the exact participation \& pleasurable experience of learning or making 
the dishes themselves is missing. If this is added in case of food especially when dining out would be a pleasurable sensory experience, hence the pleasure factor or the "feel good" factor as a result of food preparation \& consumption at a destination can be a "pull factor" and marketing and merchandising tool that must not be underestimated. For this reason, one can argue that tourists often place considerable emphasis on how they feel at a destination, and how they experience what the destination offers, by carefully selecting that special restaurant and/or food that might fulfil a particular personal desire (Richards, 2002).

Although many studies identify and address factors that affect destination choice and image, very few empirical studies address the role that gastronomy in pretext to tourism. Though majority of state \& central tourism departments pay emphasis on culinary \& tourism yet the relationship between gastronomy and tourism is affirmed in select social sciences literature, very few studies are reported in the hospitality literature that specifically address the gastronomy and tourism relationship.

\section{Review of Literature:}

The purpose of this research was to review prior studies involving gastronomy and its linkage to tourism. Moreover, its purpose is to determine how gastronomy can be utilised to promote a State like Jharkhand and can it be argued that gastronomy is a viable alternative for new destinations that cannot benefit from "sun, sea, and sand" or natural or cultural resources. Unlike other travel activities and attractions, gastronomy is available year-round, any time of day, and in any weather. Jean Anthelme Brillat-Savarin (1755-1826), undertook the first formal study of gastronomy which was most eloquently published in La Physiologie du gout in 1825. It has been translated numerous times into English as The Physiology of Taste.Source: (Jakša Kivela \& John C. Crotts)

Two hundred years ago the word gastronomy made its first appearance in modern times, in France, as a title of a poem published by Jacques Berchoux (1804). Despite the immense popularity attained by the word since then, Long (2004) first coined the term "culinary tourism" in 1998 to express the idea of experiencing other cultures through food and, incidentally, wine. (Desinano and Vigo 1994), used value chain, a common approach to tourism studies to analyse the accumulated needs of a tourist during the holiday (accommodation, catering, transport, information and entertainment) for the purpose of assessing, for example, the regional implications of tourism. In his classification of cultural attractions, Munsters (1994) identifies regional gastronomic routes as a specific cultural tourism product. Wolf (2002), however, defines culinaria and gastronomy 
tourism as "travel in order to search for, and enjoy prepared food and drink... and unique and memorable gastronomic experiences." This statement clearly suggests that when we talk about gastronomy we are not just focusing on food but also beverage. For seasoned travellers who have had many such holiday experiences,

For example, some hospitality organizations offer gourmet holidays to various destinations. For tourists, this means that the destination's restaurants' ambience and cuisine, and/or its vineyards, are legitimate sources of pleasure that generate emotions and experiences, it is hoped pleasant ones, that they are supposed to be having while on holiday (Kivela \& Chu, 2001). It must be said, however, that such pleasure does not always have an enduring effect and that it does diminish over time. Also, although tourists often dine out in search of new taste and culinary experiences, or when they discover a new vineyard, they may also encounter disappointment from time to time: an eatery or wine that is a parody of the destination's image, or what Finkelstein (1989) calls "manufactured images." Nevertheless, an increasing number of tourist destinations are very sought after because of their unique gastronomy (Hialager, 2002). These destinations are also known as the "foodie" and/or wine holiday destinations. Lifestyle and travel media also vigorously promote gastronomy, for example, magazines such as Epicure and Gourmet. In search of new recipes and taste sensations, both food critics and celebrity chefs scour the world for new and different gastronomy, rediscovering old, long forgotten recipes and discovering new ingredients and new culinary destinations.

Therefore, it is appropriate to say that the relationship between gastronomy and a tourist destination is symbiotic because the destination provides the food, recipes, chefs, and the cultural backdrop that make gastronomy an ideal product for tourist consumption (Fields, 2002; Richards, 2002; Scarpato, 2002). Simply stated, gastronomy is an inextricable part the holiday experience. Based on Cohen's (1984) phenomenological categorization of tourist lifestyles, Hialager (2003) offers a phenomenological model of culinary tourism experiences. The model of tourism and gastronomy lifestyles depicts tourist attitudes and preferences for food and beverage according to four categorizations-recreational, existential, diversionary, and experimental gastronomy tourists. The following section discusses the culinary tourism experience in the context of Hialager's model and highlights the variations in tourists' dining-related behavior.

According to Hialager (2003), the existential gastronomy tourists seek food and beverage combinations and eating experiences that foster (gastronomy) learning. For these tourists, food and beverage consumption does not only satisfy hunger and thirst but, important for them, such consumption means gaining in-depth 
knowledge about the local or regional cuisine, wine, and beverages and of the destination's culture. Existential gastronomy tourists are unlikely to be found in typical tourist restaurants or crowded chain or popular restaurants. For these tourists, the holiday's success is measured by that special restaurant "where only the locals eat," or that special vineyard. These tourists actively seek simple and unsophisticated peasant food and beverage that is prepared with care and respect to tradition; for example, Portugal offers some great gastronomy retreats that attract the existential gastronomy tourist. The existential gastronomy tourists avoid expensive restaurants not only because of the price but also because of the extravagant décor and service that often happens.

The unique features of gastronomy tourism provided by the International

Culinary Tourism Association's (2006, p. 1) Web site are,

- almost 100 per cent of tourists dine out when travelling, and each dining opportunity is a chance to get to know local food and people;

- dining is consistently one of the top three favourite tourist activities

- culinary or gastronomy art and wine tasting is the only art form that affects all five human senses-sight, sound, smell, taste, and touch;

- there is a high positive correlation between tourists who are interested in wine/cuisine and those interested in museums, shows, shopping, music and film festivals, and cultural attractions;

- interest in cuisine when travelling is not reserved to a particular age, sex, or ethnic group;

- unlike other travel activities and attractions, gastronomy is available yearround, any time of day and in any weather;

- more often than not, gastronomy tourists are "explorers"; and gastronomy is "experiential" as it satisfies new traveller demands for hands-on, interactive experiences.

\section{India \& Gastronomy:}

Age cannot wither... nor custom stale the infinite variety....

That is how Shakespeare would have undoubtedly put it.....talking about Indian Cuisine, which, with its immense variety, has carved a niche for itself internationally. People from other parts of the world, especially in the West, simply adore Indian cuisine, despite the fact that a majority of its dishes are spicy, tangy and hot! Indeed Continental as well as American cuisine (save Mexican) is rather bland when compared to their Indian counterpart. Down the centuries, Indian spices have always lured the adventurous, sea-farers and explorers to come to India 
and carry away bulk quantities to their native lands. All that is a part of our history now. These days' Indian restaurants could be easily seen in Europe and America. The diverse geographical condition of India provides variety of ingredients to give different flavours \& variety in dishes. Regional dishes of north are invariably distinct from southern Indian sub continent. The dishes from eastern part of country have their own charm while central \& western dishes do offer a great variety in taste amongst themselves. Great History of India has also a significant influence on regional specialities. Awadhi cuisine, Hyderabadi Cuisine are indeed the collection of exotic mouth watering dishes of great emperors \& nawabs of ancient India. However the regional cuisine of princely state of Rajasthan enjoys popularity amongst big part of tourists visiting India. On the survey done by the authors to understand the use of gastronomy as a tool to promote tourism it was found that ten state tourism departments namely (Andhra Pradesh, Goa, Gujarat, Haryana, Jammu \& Kashmir, Kerala, Maharashtra, Orissa, Rajasthan and Tamilnadu) are using gastronomy as a tool to tourism promotion. However the use of gastronomy is limited to information about cuisines of those sates. One important point to be noticed here is that these states are also amongst the most tourist attracting destinations in India.

(Table-1)

\begin{tabular}{|c|c|c|c|c|c|c|c|c|c|c|c|c|}
\hline Ronks & \multicolumn{2}{|c|}{ Business/Trade } & \multicolumn{2}{|c|}{ Leisure/Holiday } & \multicolumn{2}{|c|}{ Religious/Pilgrimage } & \multicolumn{2}{|l|}{ Social } & \multicolumn{2}{|l|}{ Others } & \multicolumn{2}{|l|}{ Total trips } \\
\hline 1 & Rajastton & 21 & Madhya Prodesh & 30 & West Bengal & 124 & Himachal Prodesh & 825 & Tomil Nodu & 112 & Assam & 1905 \\
\hline 2 & Madhyo Pradesh & 28 & Chattisgarh & 37 & Madhyo Pradesh & 166 & Punjab & 934 & West Bengal & 164 & Chattisgarh & 2071 \\
\hline 3 & Maharashtra & 53 & Rajasthan & 51 & Bihar & 169 & Assom & 946 & Gujarat & 178 & Gujarat & 2182 \\
\hline 4 & Chattisgarh & 54 & Bihar & 68 & Orissa & 186 & Karnataka & 1095 & Andhra Pradesh & 182 & Himachal Prodesh & 2188 \\
\hline 5 & West Bengal & 59 & Orisso & 76 & Chattisgarh & 226 & Gujarat & 1172 & Rajasthon & 193 & Andhro Pradesh & 2192 \\
\hline 6 & Kerala & 65 & Jharkhand & 86 & Kerola & 248 & Andhro Pradesh & 1387 & Maharashtro & 206 & Uttar Pradesh & 2202 \\
\hline 7 & Orissa & 73 & Uttar Pradesh & 101 & Assom & 268 & Chattisgarh & 1439 & Uttor Prodesh & 210 & Madhyo Prodesh & 2255 \\
\hline 8 & Tamil Nadu & 79 & Andra Pradesh & 103 & Rajasthan & 266 & Tamil Nadu & 1474 & Kerala & 228 & Karnatako & 2276 \\
\hline 9 & Gujarat & 89 & Maharoshtro & 116 & Uttar Pradesh & 297 & Delhi & 1475 & Madhya Pradesh & 229 & Punjab & 2317 \\
\hline 10 & Uttar Pradesh & 90 & Haryana & 132 & Himachal Prodesh & 338 & Mahorashtro & 1489 & Delhi & 258 & Bihar & 2329 \\
\hline 11 & Bihar & 101 & Assam & 149 & Uttaranchol & 361 & Uttar Pradesh & 1603 & Karnataka & 262 & Maharashtro & 2407 \\
\hline 12 & Andhro Pradesh & 115 & Kerala & 209 & Jharkhand & 375 & Uttaranchal & 1526 & Haryana & 290 & Orisso & 2426 \\
\hline 13 & Jharkhand & 116 & West Bengal & 220 & Andhra Pradesh & 406 & Bihar & 1639 & Punjab & 299 & Tamil Nadu & 2619 \\
\hline 14 & Kornataka & 138 & \begin{tabular}{|l|l} 
Uttaranchol \\
\end{tabular} & 224 & Punjab & 432 & \begin{tabular}{|l|} 
Haryana \\
\end{tabular} & 1601 & Chattisgarh & 316 & Kerala & 2649 \\
\hline 15 & Assam & 167 & Gujarat & 268 & Haryano & 436 & Orisso & 1755 & Orissa & 336 & West Bengal & 2690 \\
\hline 16 & Delhi & 188 & Tamil Nadu & 279 & Gujorat & 476 & Kerala & 1799 & Assam & 386 & Haryana & 2663 \\
\hline 17 & Haryona & 203 & Karnataka & 282 & Karnataka & 600 & Madhyo Pradesh & 1801 & Uittoranchal & 390 & Uttoranchal & 2698 \\
\hline 18 & Uttaranchol & 206 & Himachal Prodesh & 308 & Maharashtro & 543 & West Bengal & 2022 & Bihar & 453 & Rajasthan & 2763 \\
\hline 19 & Himachal Prodesh & 218 & Punjab & 319 & Tamil Nadu & 574 & Jharkhand & 2132 & Jharkhand & 472 & Delhi & 2869 \\
\hline 20 & Punjab & 333 & Delhi & 346 & Delhi & 592 & Rojasthan & 2223 & Himachal Pradesh & 501 & Jharkhand & 3181 \\
\hline & All States & 95 & All States & 153 & All States & 358 & All States & 1531 & All States & 240 & All States & 2379 \\
\hline
\end{tabular}

Relative Ranking of States by Tourists Per 1000 Trips - All India Source Domestic Tourism Study. By National council of Applied Economic Research. 
It has also been found that food holds third major share in tourist expenses. A total of close to 40 percent of average expenditure per trip is spent on food (including processed food), clothing and accommodation. The remaining 35 percent is accounted for by medicines, durable goods, gems and jewellery, etc. (Table-2) Thus contribution on food can be a good revenue generator. If gastronomy tourism used fully as marketing tool can trigger increase in revenue manifold. Also it is clear from the report generated by NCAER for Department of Tourism Govt. of India that a large part of tourist expenditure goes in transportation thus traveling long distances for food \& gastronomy can not be a major hindrance in promoting gastronomy tourism. In terms of development of formal literature development of culinary. Ms. Krishna Arora, Thangam E Philip, Dr. B.K.Chakravarty have contributed various culinary books both for academic as well as practical purposes in India. In promotion of culinary to masses Sanjeev Kapoor, Tarala Dalal and other Indian authors have contributed books in the field of culinary. Hotel Industry in India has also a significant contribution in terms of gastronomy research development. Taj Group of Hotels, Oberoi's have their research \& development sections which work to excel in the gastronomy. In the process of opening Udaivilas - an Oberoi Resort in Udaipur. The Pre opening chefs explored the gastronomy of Udaipur \& Rajasthan in order to provide authentic food to the guests. However actual participation in learning gastronomy by travelers/ guests is restricted to limited upscale hotels. Authors here believe that full benefits can be derived of gastronomy tourism only if it is practiced properly.

Table-2 (Average Expenditure per Trip in INR)

\begin{tabular}{lccc}
\hline Items & Urban & Rural & All India \\
\hline Transport & 574 & 261 & 339 \\
Accommodation & 148 & 50 & 82 \\
Food & 230 & 124 & 150 \\
Cloths & 374 & 217 & 256 \\
Processed food & 59 & 42 & 46 \\
Intoxicants & 21 & 16 & 18 \\
Durable goods & 72 & 41 & 48 \\
Footwear & 41 & 28 & 31 \\
Toiletries & 33 & 25 & 27 \\
Gems \& jewellery & 55 & 36 & 41 \\
Books \& magazines & 14 & 8 & 10 \\
Medicines & 59 & 99 & 89 \\
Others & 363 & 214 & 251 \\
\hline Total & 2043 & 1160 & 1389 \\
\hline
\end{tabular}

Source- Domestic Tourism Survey by National Council of Applied Economic Research -2002-2003 
Jharkhand State: Jharkhand is the $28^{\text {th }}$ State of Indian Union. Carved out from erstwhile Bihar the region, rich history \& culture goes thousand of years beyond its recent foundation. Jharkhand has 32 primitive tribal groups. Their art, music, culture, food, dances and other such things makes it a unique identity. The state has tumbling beauty, heavily forest hills, wildlife, flora \& fauna, enchanting rivers \& majestic waterfalls. Well endowed in mineral wealth Jharkhand is the country's foremost producer of iron ore, copper ore, mica \& asbestos. The capital of the state is Ranchi which is a non Himalayan hill station. The state enjoys a salubrious climate extending tourists an invitation round the year. Various festivals like Sarhul, Dansai, Sohrai, Rohin Hal Punhya, Tusu \& other such are celebrated round the year. Jharkhand is also a land of fairs. Various melas (fairs) e.g Kunda Mela (held during shivratri focusing on cattle sale) Kolhua Mela, Chatra Mela, Kundri Mela, Lawalong Mela, Bhadli mela and other such are organised from time to time. Besides above mentioned the state tourism department also organises Adventure fairs, tourism expos, shrawani mela (religious fair) in the state. The state has national parks \& wild life sanctuaries in Betla, Palamau, Dalma, Hazaribagh offering their own moments of charm. Exquisite terracotta temples made up of burnt bricks \& lime mortar with exteriors decorated from terracotta plates belonging to the late medieval age located at Maluti. Deoghar (abode of gods) Baidyanath Dham one of the 12 Jyotirlingas \& the only kamnalinga in the country attracts about fifty lakhs odd pilgrims from all over the country. Jain temples at parasnath hills where 20 of the 24 Tirthankars (except Tirthankars Rishabhdev, Vasupujay, Neminath \& Mahavir) were liberated from the cycle of birth \& death in what is now known as Sammed Shikhar are the prime reasons of visit of Jain religious tourists. Besides above mentioned Jharkhand had places to discover, rejuvenate, retreat, adventure and heritage destinations. Truly as described by Jharkhand Tourism Department - "Jharkhand - Unspoilt by man or time" is a wonderful tourist destination. It's a complete destination both for the first time visitor \& the return traveller. Despite all these pull factors Jharkhand doesn't enjoy a good share in tourism recipients \& thus the income from tourism activity. May be that the pre tested 4S formula (Sun, Sand, Sea \& Sex) does not fits in the tourism phenomena of the state. In order to trigger tourism activity the authors here felt the need of gastronomy tourism as a tool for promoting Jharkhand as a tourist destination.

\section{Objective:}

- Newly built state of Jharkhand must be having some regional specialities in terms of Gastronomy - To know about regional gastronomy of Jharkhand.

- Use of gastronomy as a tool to market Jharkhand as a tourist destination. 


\section{Research Methodology:}

The paper is an exploratory research, which has been concerned with the analysis of available data as well as generation of primary data in terms of identification of regional cuisine. The study has been carried out in the state of Jharkhand. Districts including state capital Ranchi, Deoghar, Jamshedpur and Hazaribagh have been surveyed by visiting their Hotels, population in suburbs \& rural areas. To know their regional gastronomy. The random sampling technique has been adopted and Jharkhand has been the Universe.

\section{Findings:}

The below mentioned findings of the research were surprisingly with terrific results giving in-depth information about regional gastronomy. Though the influence of cooking styles of Bihar, Orissa, Chattisgarh and West Bengal was dominant yet few Specialities could be traced out i.e. Phooto, Khukri, Bamboo Shoot, Pumpkin Flowers, Rice, Sal Leaves, Chana Peas, Urad Dal, Aloo, Mutton, Ginger, Gram Flour are few key ingredients of typical Jharkhandi Cuisine. The state has got a lot of authentic food to be offered to the tourists. Phooto is tiny, pearl white; chewy is generally available in the monsoons. Phooto is cooked with onion, garlic, ginger, turmeric \& salt with cardamom \& black pepper tastes well with both rice \& parantha's. Khukri can be considered to be a distinct cousin of Phooto. It looks gorgeous with a flounce in its torso \& long shapely roots. They resemble to Chanterelle Mushrooms. It is woody \& has meaty flavour. A typical Jharkhandi meal includes Dhuska, which is a thick salty pancake made up of urad dal \& rice. Dhuska batter is left to ferment in the sun \& then deep fried in oil. However on text it may appear similar to a dosa but tastes very different. It is generally offered with spicy potato or tangy mutton and no curry is served. Chilka is worth comparable to crepe suzette. It is a rice \& lentil pancake also served in many local restaurants. Sal Leaves available in abundance in state ( $\mathrm{Sal}$ is the state tree of Jharkhand). Urad Dal, Rice, Ginger Juice \& salt are wrapped triangularly in Sal leaves and steamed for about 25 Minutes makes a Dudku Roti. Bamboo shoot pakoras are relished by the people in state. Bamboo shoots are soaked in water for about one week and then deep fried in besan batter gives a tangy taste in form of pakoras. Beng Saag, is also one of the typical Jharkhandi Meal. Beng literally translates into Toad that is heart shaped \& grows near river. Nanki Bari with eggplant, tomato chutney, stale rice soaked overnight, Pumpkin Flowers fried in besan batter are also included in a Jharkhandi Meal. In sweet dish dakkan dabba is served which is made of rice cooked in a special earthen pot without oil. They look like round stout puris floating in milk however tastes fantastic. Thikur, Dudhouri \& Arsa is also included in desserts. Arsa is generally dry, brittle fried sweet \& adorned with seasam seeds. No food can be 
complete without beverages. How about if we say that Jharkhandi's have their home made scotch. Perhaps it can be said handiya is to tribals what scotch is to hip. Handiya could be seen in almost every house. It is white, tangy, whey-like drink that is generally accompanied with roasted chana or peas. One can easily find women sitting under trees in haats, local markets with large earthen or aluminium pots \& recycled beer/alcohol bottles offering home made handiya at a nominal cost.

Despite such a variety in Jharkhandi food the dominance of Bengali, Orriya \& Bihari food is very well accepted \& appreciated in the state. However the limitation factor is that only a limited number of restaurants \& other F\&B Outlets promote Jharkhandi food thus many a times visitors are unable to relish the food of state. It is projected that the tourist inflow is going to grow many fold \& thus the requirement of food outlets would be there. The hosting of National Games in 2007 \& projections of Bihar State Tourism Development Corporation \& Jharkhand State Tourism Development Corporation in their 20 years prospective plan would surely increase tourist traffic.

\section{Table-3}

\begin{tabular}{|c|c|c|c|}
\hline Xor & 8301165416 & $6 \%$ mats & $\% 16$ \\
\hline 2002 & 3843992 & 4022 & 3848014 \\
\hline 2003 & 3959312 & 4102 & 3963414 \\
\hline 2004 & 4078091 & 4184 & 4082275 \\
\hline 2005 & 4200434 & 4268 & 4204702 \\
\hline 2006 & 4326447 & 4354 & 4330800 \\
\hline 2007 & 4456240 & 4441 & 4460681 \\
\hline 2008 & 4589927 & 4529 & 4594457 \\
\hline 2009 & 4727625 & 4620 & 4732245 \\
\hline 2010 & 4869454 & 4712 & 4874166 \\
\hline 2011 & 5015537 & 4807 & 5020344 \\
\hline 2012 & 5166003 & 4903 & 5170906 \\
\hline 2013 & 5320984 & 5001 & 5325984 \\
\hline 2014 & 5480613 & 5101 & 5485714 \\
\hline
\end{tabular}


Table-3 (Contd.)

\begin{tabular}{|c|c|c|c|}
\hline ISor: & 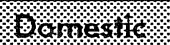 & W. & 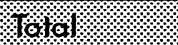 \\
\hline 2015 & 5645031 & 5203 & 5650234 \\
\hline 2016 & 5814382 & 5307 & 5819689 \\
\hline 2017 & 5988814 & 5413 & 5994227 \\
\hline 2018 & 6168478 & 5521 & 6174000 \\
\hline 2019 & 6353533 & 5632 & 6359164 \\
\hline 2020 & 6544139 & 5744 & 6549883 \\
\hline
\end{tabular}

Source:- Preparation of 20 years Perspective Plan For The state of Jharkhand Final Report March 2003 By- ORG-MARG RESEARCH LIMITED NEW DELHI

Projected Traffic flow in the State The above projection is based on the tourist visits at prime tourist locations of the State as received from Bihar State Tourism Development Corporation, which used to look after all the tourist spots of the State of Jharkhand, prior to the separation from Bihar.

Source:- Preparation of 20 years Perspective Plan For The state of Jharkhand Final Report March 2003 By- ORG-MARG RESEARCH LIMITED NEW DELHI

Effective use of gastronomy can be used as a tool to promote the state tourism $\&$ can be a good revenue generator to the host population.

\section{Conclusion \& Suggestions:}

Though many efforts have been done by State Tourism Department, Jharkhand Tourism Development Corporation and other organisations in order to trigger tourism in Jharkhand below mentioned are few suggestions which could be used to promote the state tourism by gastronomy tourism.

- Developing of Menu on Regional Cuisine \& implementing in State Tourism Development run hotels \& restaurants. Also promoting it in other commercial restaurants.

- Designing \& implementation of a package tour in order to suit needs of gastronomy tourists. Being on vacation/tour tourists availing opportunity to 
learn regional gastronomy in the hotels or local restaurants involving more of active tourist participation.

- Organising camp tours in wild Jharkhand and implementing local gastronomy.

- Setting of Hotel Management Institutes in state in order to provide trained manpower to meet needs of future.

- Making gastronomy tourism feasible for domestic \& mid- segment tourists.

- Conducting/Granting research programmes to promote \& know more about gastronomy of State.

- Display of cuisine on state tourism Department's Website so as to provide a wide accessibility of state's cuisine worldwide.

- Training of Staff of Hotels run by JTDC for new programmes.

- Effectively using menu engineering to promote state cuisine \& maximise sales as well as revenue.

- Developing literature on state gastronomy \& proving popularity to it.

- Using promotional tools \& seeking help of agencies to promote gastronomy.

- Making F\&B outlets trendy, appealable \& adding latest growth, ingredients \& recipes in order to compete with growing $M N C^{\prime}$ s.

- Making provision of self contained accommodation for recreational gastronomy tourists.

- Special Provision for diversionary gastronomy tourists who generally dislike exotic foods

As the 4S formula doesn't suit much in Jharkhand Gastronomy Tourism can be viable alternative for state \& other new destinations. Gastronomy can add value to the tourist experience and is associated with quality tourism for travellers in search of new products and experiences that yield a high level of satisfaction, wine tourism being a good example. Gastronomy and wine have created demand for short and/or weekend holidays; In this context, foodservice industries State Tourism Department must accept that the role of gastronomy in modern tourism. These gastronomy tours should specifically focus on food and food culture, beverage indigenous cuisine, dining out, cooking, and shopping for foods at local markets. Gastronomy is often the driving force behind the revival of tourism for destinations that are struggling for one reason or another. Jharkhand can explore the potential of gastronomy tourism to trigger tourism activity. 


\section{References:}

1. Anne-Mette Hjalager and Greg Richards, Tourism and Gastronomy, Routledge. London. 2002 Pp: iii-36

2. Chakravarti, B.K, Hotel Management Theory Vol. I \& II. APH Publishing Corporation, New Delhi, 1999.

3. Discover Jharkhand, Nov 2006, DOT Govt of Jharkhand.

4. Domestic Tourism Survey by National Council of Applied Economic Research -2002-2003

5. James J. Wilton and Norma Polovitz, Collecting and Using Visitor Spending Data, Journal of Travel Research, Vol. 45, August 2006, 17-25

6. Jaksa Kivela, John C. Crotts, Tourism \& Gastronomy: Gastronomy's influence on how tourists experience a destination, 2006 International Council on Hotel, Restaurant and Institutional Education; Journal of Hospitality \& Tourism Research, Vol. 30, No. 3, August 2006, 354-377

7. Kevin Fields, Demand for the gastronomy tourism product: motivational factors

8. Market pulse report, Ministy of Tourism, Govt. of India Feb 2004.

9. Wolf, E. (2002). Culinary tourism: A tasty economic proposition. Retrieved July 12, 2004, from http://www.culinarytourism.org

10. http://www.incredibleindia.com

11. http://www.jharkhand.nic.in

12. http://www.questia.com/PM.qst? $a=0 \& d=102939324$

13. hHtp://www.shubhyatra.com/states.html 